\title{
ANALISIS KEPUASAN PENGGUNA WEBSITE PERPUSTAKAAN MENGGUNAKAN STRUCTURAL EQUATION MODELLING (SEM)
}

\author{
Trisna Silvia, Second B. Zainudin Ismail, Third C. Muhamad Akbar \\ Program Magister Teknik Informatika \\ Universitas Bina Darma \\ email :trisnasilvia1@gmail.com \\ J1. A. Yani No. 12, Palembang 30624, Indonesia
}

\begin{abstract}
Manfaat dari adanya website internet tidak akan mencapai hasil maksimal jika mahasiswa atau dosen sebagai konsumen dari website Perpustakaan merasa tidak puas akan layanannya. Penelitian ini bertujuan untuk menguji model yang menjelaskan kepuasan mahasiswa dan Dosen saat menggunakan website Perpustakaan sebagai pendukung perkuliahan tatap mukanya. Penelitian ini disusun berdasarkan dengan menggunakan metode yang sering dipakai oleh peneliti terdahulu yaitu structural equation modelling(sem). Penelitian ini dilakukan di Perguruantinggi Stie Mura Lubuklinggau. Data responden sebanyak 100 mahasiswa Tergolong dari mahasiswa dam dosen dan Structural Equation Modelling digunakan untuk menguji hipotesis - hipotesis darikarateristik layanan wesbite Perpustakaan, motivasi menggunakan website dan budaya menggunakan internet terhadap kepuasan konsumen.
\end{abstract}

Kata kunci: kepuasaan Pengguna, website Perpustakaan, structural equation modelling

\begin{abstract}
The benefits of an internet website will not achieve maximum results if students or lecturers as consumers of the Library website feel dissatisfied with the service. This study aims to test the model that describes the satisfaction of students and lecturers when using the Library website as a supporter face-to-face lecture. This research is based on the method used frequently by the previous researcher that is structural equation modeling (sem). This research was conducted in Perguruantinggi Stie Mura Lubuklinggau. The data of 100 respondents of students Classified from students and lecturer Dect and Structural Equation Modeling used to test the hypotheses of the wesbite library service characteristics, the motivation to use the website and culture using the internet to customer satisfaction.
\end{abstract}

Keywords: User satisfaction, Library website, structural equation modeling 


\section{PENDAHULUAN}

Kemajuan teknologi di era globalisasi saat ini khususnya dibidang Technology Informasi (IT) pada saat ini tidak bisa dipungkiri lagi manfaatnya.Perkembangan dunia IT begitu pesatnya.Dimana hampir disetiap sudut kehidupan manusia menggunakan teknologi, perkembangan IT yang terus berkembang dari hari kehari membuat kita bisa bebas melakukan kegiatan dengan efisien, efektif dan kebutuhan terpenuhi.Di era globalisasi yang tengah berkembang pesat seperti sekarang ini perkembangan berbagai macam tekhnologi tidak diragukan lagi. Dalam perkembangan masa kini, khususnya Indonesia mempunyai peranan penting dalam mengembangkan tehnologi informasi dalam dunia pendidikan yaitu sebuah website perputakaan .Menurut Dewiyana (2008)Pemanfaatan perkembangan IT hamper dipakai disegala bidang, terutamadalam bidang pendidikan, Adapun contoh penerapan IT website manfaat IT didunia pelayanan penelitian ini mengungkapkan bahwa pengembangan perpustakaan digital adalah berkaitan dengan antarmuka, antarmuka perpustakaan digital menjadi jembatan yang menghubungkan kebutuhan informasi pengguna dengan sumber-sumber dan layanan, IT khusunya dibidang pendidikan perpustakaan online dapat meningkatkan pelayanan, akurasi dan efisiensi dokumentasi serta mempermudah

pengguna dalam menghubungkan kebutuhaninformasi pengguna dengan sumber-sumber danlayanan yang ada di perpustakaan.Penerapan sistem perpustakaan digital ini akan sangat membantu para pengguna perpustakaan, bahwa penerapan sistem perpustakaan digital ini akan sangat membantu pustakawan dan para pengguna perpustakaan. Bagi pustakawan, sistem ini akan sangat membantu pekerjaan mereka melalui fungsi-fungsi otomasi yang tersedia, sehingga proses pengelolaan perpustakaan akan menjadi efektif dan efisien.Susanto (2010) Sistem ini juga sangat membantu pengguna perpustakaan dalam mengakses semua informasi yang tersedia pada database perpustakaan dari contoh diatas disimpulkan bahwa peran peran IT dibidang pendidikan khususnya di bidang perpustakaan mempunyai dampak yang sangat besar dalam pelayanan kepada pengguna perpustakaan dan pustakawan .Perpustakaan adalahtempat sebuah koleksi buku dan majalah. Walaupun dapat diartikan sebagai koleksi pribadi perseorangan, namun perpustakaan lebih umum dikenal sebagai sebuah koleksi besaryang dibiayai dan dioperasikan oleh sebuah kota atau institusi, serta dimanfaatkan oleh masyarakat yang rata-rata tidak mampu membeli sekian banyak buku atas biaya sendiri.

Perpustakaan tersebut adalah tujuan perpustakaannya, koleksi yang tersedia, masyarakat yang dilayani, badan atau pihak yang berwenang menyelenggarakan perpustakaantersebut.

Internasional Federation of Liberary Associantion (IFLA) mengelompokan jenis-jenis perpustaka ayaitu :1. Perpustaka an Nasional (National Library),2. Perpustakaan Umum (Public Library), 3. Perpustakaan Perguruan Tinggi (University Library) 4PerpustakaanSekolah (School Library)5. Perpustakaan Khusus (Specia lLibrary).Selainkelima jenisperpustakaan yangtersebut di atas, kita mengenal juga jenis-jenis perpustakaan yanglain yaitu :6. Perpustakaan Wilayah, 7. Perpustakaan Keliling.

Banyak penelitian terdahulu yang melakukan investigasi peranan IT di pelayanan khusus nya perpustakaan, seperti yang di utarakan oleh Ishak (2015) meneliti penerapan ITmasyarakat pengguna perpustakaan menghendaki perpustakaan menjadi rightinformation, right user dan right now. Artinya perpustakaan dituntut untuk memberikan layanan informasiyang tepat, pada pengguna yang tepat dan waktu yang cepat.

Dari beberapa penelitian terdahulu diatas, dapat disimpulkan penelitianterdahulu hanya fokus pada pemanfaatan infrastruktur untuk peningkatan pelayanan kepada pengguna dan pustakawan , tetapi hanya sedikit yang melakukan investigasi tentang pelayanan perpustakaan .

Begitu juga sama dengan sistem yang ada pada STIE-MURA Lubuklinggau masih berfokuskan pada infrastruktur saja tanpa memikirkan bagaimana agar pelayanan perpustakaan bisa berjalan dengan baik.. 
Dari masalah diatas, penulis ingin mencoba mengevalusi pengguna dan pustakawan yang dimiliki oleh pihak STIE-MURA Lubuklingaau, dalam pelayanan perpustakaan . Hal ini dikarenakan dalam pengolahan sistem informasi perpustakaan pasti juga tidak terlepas dari peranan yang bertugas mengoperasikan dan menjalankan aplikasi tersebut dalam hal ini sebagai pustakwan. Penelitian mengukur dan mengevaluasi kepusasan pengguna dalam Sistem Informasi perpustakaan online yang ada pada perguruantiingi STIE-MUSI RAWAS. Sehingga dengan adanya penelitian ini dapat mengoptimalkan pelayanan kepada pengguna yang menggunakan aplikasi dalam keperluan peminjaman buku, Maka dari penjelasan diatas penulis mempertimbangkan mengambil judul "ANALISIS KEPUASAN PENGGUNA WEBSITE PERPUSTAKAAN MENGGUNAKAN STRUCTURAL EQUATION MODELLING(SEM).

\section{METODOLOGI PENELITAN}

\subsection{MetodologiPenelitian}

Pada penelitian ini penulis menggunakan kerangka konseptual atau kerangka berfikir untuk mengindentifikasi faktor-faktor kepuasan pengguna pada perpustakaan STIE-MURA LUBUKLINGGAU.Temuan hasil penelitian yang telah ada sangat membantu dan mempermudah peneliti membuatkerangka konseptual. Kerangka konseptual diharapkan akan memberikan gambaran dan mengarahkan asumsi mengenai variabel-variabel yang akan diteliti. Kerangka konseptual memberikan petunju kepada peneliti di dalam merumuskan masalah penelitian.

Kerangka yang dibuat diuji dan di validasi menggunakanstructural Equation Modelling $(S E M)$. Sebuah pertanyaan penelitian dirumuskan sebagai berikut apa faktor dari kepuasan pengguna Perpustakaan di STIE-MURA LUBUKLINGGAU

\subsection{TeknikPengumpulan Data}

Data yang digunakan dalam penelitian terdiri dari data primer dan sekunder. Data primer diperoleh melalui pengamatan langsung di lapangan dengan berpedoman pada instrumen penelitian menggunakan kuesioner, sedangkan data sekunder diperoleh dari berbagai laporan dan publikasi yang relevan dengan penelitian.

\subsection{Populasidansampel}

\section{a. Populasi}

Populasi adalah wilayah generalisasi yang terdiri atas obyek/subyek yang mempunyai kualitas dan karakteristik tertentu yang diterapkan oleh peneliti untuk dipelajari dan kemudian ditarik kesimpulannya (Sugiyono 2012:80). Populasi dalam penelitian ini adalah pelanggan yang pembeli berjumlah 2198 pelanggan dengan perincian selama 8 bulan terhitung dari bulanFebruari 2016 sampai dengan September 2016 sebagai berikut:

Tabel 1.Total Populasi Yang MenggunakanSistem

\begin{tabular}{|c|c|l|c|}
\hline No & \multicolumn{2}{|c|}{ Nama } & Jumlah \\
\hline \multirow{2}{*}{ 1. } & \multirow{2}{*}{ Mahasiswa } & Manajemen & 1424 \\
\cline { 3 - 4 } & & Akuntansi & 481 \\
\hline \multirow{2}{*}{ 2. } & \multirow{2}{*}{ Dosen } & DosenTetap & 30 \\
\cline { 3 - 4 } & \multicolumn{2}{|c|}{ DosenTidakTetap } & 11 \\
\hline & \multicolumn{2}{|c|}{ Total Responden } & 1946 \\
\hline
\end{tabular}


b. Sampel

Populasi adalah wilayah generalisasi yang terdiri atas obyek/subjek yang mempunyai kualitas dan karakteristik tertentu yang ditetapkan peneliti untuk dipelajari dan kemudian ditarik kesimpulan (Sugioyono, 1999).Populasi dalam penelitian ini adalah seluruh STIE-MURA LUBUKLINGGAU.

Sampel adalah sebagian dari populasi, dengan meneliti sebagian dari populasi, diharapkan hasil yang diperoleh akan dapat menggambarkan sifat populasi yang bersangkutan. Karakterisitik dari sampel yang akan dijadikan responden dalam penelitian ini yaitu pengguna website Perpustakaan STIE-MURA LUBUKLINGGAU

Tabel 2.Beberapa sample dankarakteristik yang akandiuji

\begin{tabular}{|l|l|l|}
\hline \multicolumn{2}{|c|}{ Sampel } & Karakteristik \\
\hline$\bullet \quad$ Perpustakaan & STIE- & Yang menggunakan Aplikasi Website Perpustakaan \\
MURA & & STIE-MURA LUBUKLINGGAU. \\
\hline
\end{tabular}

Dari table di atas dapat disimpulkan dari 1sampel website perpustakaan yang ada di STIE-MURA lubuk linggau.

Jumlah sampel yang akan di ambil di STIE-MURA LUBUKLINGGAU yang ada di u dapat dilihat pada table berikut.

Tabel 3.Jumlah Sampel Yang akan diambil di Stie-Mura Lubuk linggau

\begin{tabular}{|l|l|}
\hline \multicolumn{1}{|c|}{ Item } & \multicolumn{1}{|c|}{ JumlahRespondenPelangganSpeedy } \\
\hline Mahasiswa jurusan Manajemen & 40 \\
Mahasiswa Jurusan Akuntasi & 40 \\
DosenTetap & 15 \\
Dosen Tidak Tetap & 5 \\
\hline Jumlah & 100 \\
\hline
\end{tabular}

Responden yang akan dijadikan sampel dalam penelitian ini diambil sebanyak 40 orang untuk jurusan manajemen,40 orang untuk jurusan akuntansi, 15 orang untuk dosen tetap dan 5 orang untuk dosen tidak tetap.

\subsection{Teknik Analisa Data}

\subsubsection{Structural Equation Modelling (SEM)}

Dengan memperhatikan model penelitian,untuk mendapatkan data atau fakta yang bersifat teoritis yang berhubungan dengan kepustakaan dengan cara mempelajari literature,jurnal-jurnal penelitian,bahan kulia dan sumber-sumber lain yang ada hubungan dengan permasalahan yang penulis bahas .dan tahapan penelitian yang telah diformulasikan sebelumnya, teknik yang tepat untuk digunakan dalam penelitian ini, adalah model Structural Equation Modelling (SEM). 
Selain itu melalui penelitian pustaka,pengumpulan data jugadigunakan dengan cara menggunakan kuisioner.Kuisioner berisi pertanyaan-pertanyaan yang dibuatuntuk mengetahui bagaimana pengaruh antara variable persepis Kemudahanmenggunakan (Perceived Ease of Usel PEOU),Persepsi Kaemanfaatan ( Perceived Usefulness/PU), Sikap pengguna (attitude Toward Using/ATU),Prilaku pengguna(Behavioral Intention ToUse/ITU), dan Prilaku nyata (Actual System Usage/ASU). dari responden terhadap

PerpustakaanSTIE-MURALUBUKLINGGAU,Structural Equation Modelling (SEM).menguji suatu rangkaian hubungan saling ketergantungan antar variabel secara simultan Teknik ini terutama sangat bergunan apabila satu variabel dependen menjadi variabel independen dalam hubungan persamaan selanjutnya. Alasan digunakan Structural Equation Modelling (SEM).dalam penelitian ini adalah berdasarkan pertimbangan bahwa (1)Tinggkat kepercayaan individu bahwa penggunaan teknologi akan mengkatjan kinerjanya,dan persepsi kemudahan penggunaan (perceived usefulness) secara simultan sekaligus memberikan efisiensi analisis statistika, dan (2) Kemampuannya untuk mengukur dan mengembangkan kepuasan pengguna perpustakaan STIE-MURA LUBUKLINGGAU .

\section{HASIL DAN PEMBAHASAN}

\subsection{Hasil}

Berdasarkan data yang diperoleh dari hasil survai di Stie-Mura di kota lubuklinggau dengan menggunakan kuesioner (data terlampir), maka dapat diperoleh karakteristik dari Pengguna Website perpustakaan secara umum adalah sebagai berikut :

\section{Reliability}

Dalam tabel berikut ini adalah hasil penghitungan responden keseluruhan ,Yang dihitung menggunkan bantuan program spss 22 .

Tabel 4. Case Processing Summary

\begin{tabular}{|c|c|c|c|}
\hline & $\mathrm{N}$ & $\%$ \\
\hline \multirow[t]{3}{*}{ Cases } & Valid & 100 & 100.0 \\
\hline & Excluded $^{\mathrm{a}}$ & 0 & .0 \\
\hline & Total & 100 & 100.0 \\
\hline
\end{tabular}

Tabel 4. Realibility Statistics

Reliability Statistics

\begin{tabular}{|c|c|}
\hline Cronbach's Alpha & $\mathrm{N}$ of Items \\
\hline .805 & 7 \\
\hline
\end{tabular}

Tabel 6.Perhitungan kuisioner Berdasarkan jenis Kelamin

jenis_kelamin

\begin{tabular}{|l|l|r|r|r|r|}
\hline \multicolumn{2}{|c|}{} & Frequency & Percent & Valid Percent & \multicolumn{2}{c|}{ Cumulative Percent } \\
\hline \multirow{3}{*}{ Valid } & laki-laki & 58 & 58.0 & 58.0 & 58.0 \\
\cline { 2 - 6 } & perempuan & 42 & 42.0 & 42.0 & 100.0 \\
\cline { 2 - 6 } & Total & 100 & 100.0 & 100.0 & \\
\hline
\end{tabular}




\subsection{Pembahasan}

Dalam penelitian ini tidak semua data yang didapatkan dari hasil pengisian kuesioner oleh responden dikatakan layak untuk diproses lebih lanjut.Data kuesioner dikatakan tidak layak, apabila butir pertanyaan yang tidak dijawab atau pengisiannya tidak sesuai dengan petunjuk yang telah ditentukan.Jika semua butir pertanyaan yang ada dijawab sesuai dengan cara pengisian kuesioner, maka data kuisoner tersebut dikatakan layak sehingga dapat diolah lebih lanjut. Data yang terdapat pada tabel dibawah ini merupakan hasil jumlah kuisoner yang layak untuk diolah pada proses selanjutnya maupun tidak layak.

\begin{tabular}{|c|c|c|}
\hline \multicolumn{2}{|c|}{ Tabel 7.Hasil Penyebaran Kuisoner } \\
\hline $\begin{array}{c}\text { Jumlah kuisoner yang } \\
\text { disebarkan }\end{array}$ & $\begin{array}{c}\text { Jumlah kuisoner yang } \\
\text { layak }\end{array}$ & $\begin{array}{c}\text { Jumlah kuisoner yang } \\
\text { tidak layak }\end{array}$ \\
\hline 100 & 100 & 0 \\
\hline
\end{tabular}

\subsubsection{Frequencies Statistics}

Dari data table Statistics di bawah ini Dapat diihat bahawa dari hasil jawaban responden yang mengisi kuisioner yang di sebarkan oleh peneliti dan yang telah di hitung menngunakan Spss 22 sebagai media perhitungan validitas dan reabilitas.

Tabel 8.Statistics Keseluruahan Kuisioner

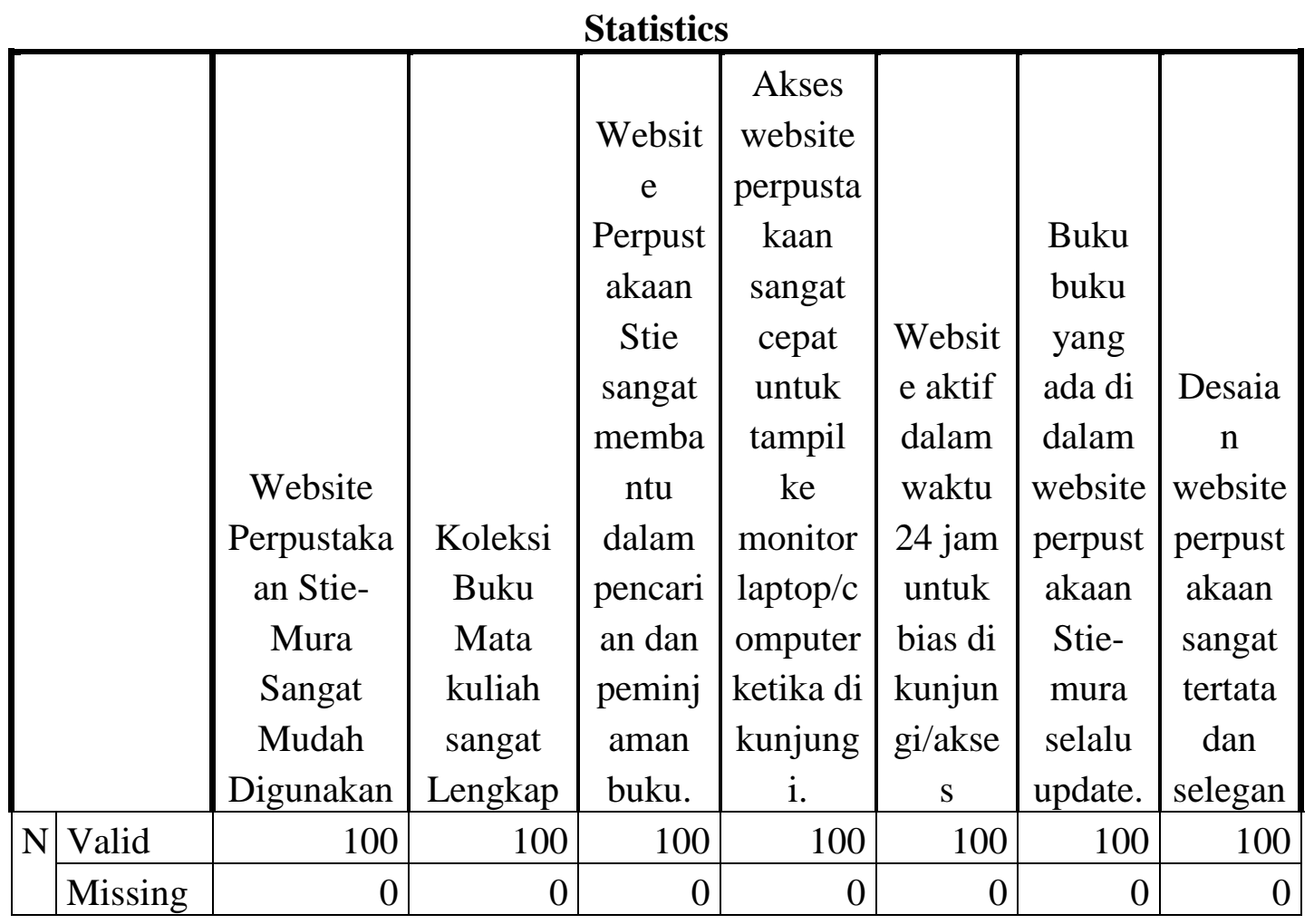




\begin{tabular}{|l|r|r|r|r|r|r|r|}
\hline Mean & 3.82 & 4.08 & 3.68 & 3.90 & 3.89 & 4.03 & 3.95 \\
\hline Median & 4.00 & 4.00 & 4.00 & 4.00 & 4.00 & 4.00 & 4.00 \\
\hline Mode & 4 & 4 & 4 & 4 & 4 & 4 & 4 \\
\hline Sum & 382 & 408 & 368 & 390 & 389 & 403 & 395 \\
\hline
\end{tabular}

\section{KESIMPULAN}

Berdasarkan analisis yang telah dilakukan pada penelitian ini, maka dapat ditarik kesimpulan sebagai berikut:

1. Tidak puasnya Pengguna Website Perpustakaan Stie Mura Lubuklinggau Karena Koleksi Buku Yang tidak Terupdate dengan kebutuhan dosen dan kebutuhan mahasiswa di STIEMURA LUBUKLINGGAU.

2. Tidak puasnya pengguna dikarenakan penggunaan system informasi yang disediakan begitu rumit untuk digunkan oleh pengguna website perpustakaan yang didominan oleh mahasiswa dan dosen manajeman dan akuntasi yang tidak ahli dalam bidang IT.

3. Tidak puasnya Pengguna website Perpustakaan Stie-mura lubuklinggau dikarenakan banyaknya konten dan gambar yang di tampilkan sehingga membuat website terlalu lama untuk tampil kelayar monitor secara keseluruhan, sehingga menunggu waktu yang lumayan lama ketika di akses/dikunjungi.

\section{Referensi}

Arikunto, Suharsimi. 2006. Prosedur Penelitian: Suatu Pendekatan Praktik. Edisi Revisi VI. Jakarta:Rineka Cipta.

Ajzen,icek.1988.Attiudes,Personality,and Behavior.M ilton -Keynes, England: openUniversity press\&Chicago,IL:Dorsey Press

Al Fatta,Hanif 2007."Analisis dan Perancangan Perancangan Sistem Informasi” Yogyakarta Grafindo Persada.

Ari Kunto,Suharsimi. 2006.”Prosedur Penelitian”Jakarta:PT Rineka Cipta

Al Fatta , 2007Analisis dan Perancangan Sistem Informasi

Arms dalam Pendit, 2000 Perpustakaan Digital: Sebuah Impian dan Kerja Bersama. Jakarta: Sagung Seto.

Davis.1989.Perceived Usefullness, Perceived Ease Of use,end user acceptance of Information technology.MIS Quartely (73((3),319-340

Davis,Hughb And Jerssie hey, Auomatic Extraction Extraction of hypermedia bu ndlles from the Digital Library (longman,1999)

Dewiyana (2008) Kompetensi dan Kurikulum Perpustakaan 
Darmono, 2001 Manajemen Perpustakaan

Fitriasari dan Arnos Kwary, 2005 Faktor Faktor Yang berpengaruh Pada Tingkat kepuasan Pengguna Sistem Informasi Berbasis Web

F. Nash, 1995 PengenalanSistemInformasiPerpustakaan .

Gondodiyoto 2003 Aplikasi Analisis Multivariate Dengan Program SPSS

Ibrahim, 2011 Pengelolaan Perpustakaan Sekolah

Jogiyanto,1995 Analisis dan Desain Sistem Informasi \& Pendekatan.

Jurnal Ilmiah Manajemen Bisnis, Vol. 10, No. 3, September 2010

Kristanto, 2008 Perancangan Sistem Informasi dan Aplikasinya

Kadir ,2002 Pengenalan Sistem Informasi Perpustakaan

Jogiiyanto,Hartono,2003.” Analisis dan desain system informasi:Pendekatan TerstrukturTeori dan Praktek Aplikasi Bisnis'”.Yogyakarta:andi offset 